\title{
TERESA, ¿REVISTA PARA TODAS LAS MUJERES? GÉNERO, CLASE Y ESPACIOS DE LA VIDA COTIDIANA EN EL DISCURSO DE LA SECCIÓN FEMENINA (1960-1970)'
}

\author{
Teresa, a journal for all women? \\ Gender, class and the space of everyday life \\ in the Sección Femenina's transition to democracy (1960-1970)
}

\author{
INBAL OFER \\ The Open University of Israel \\ inbalof@openu.ac.il \\ Cómo citar/Citation \\ Inbal, O. (2017). \\ Teresa, ว̇revista para todas las mujeres? Género, clase y espacios \\ de la vida cotidiana en el discurso de la Sección Femenina (1960-1970). \\ Historia y Política, 37, 121-146 \\ doi: https://doi.org/10.18042/hp.37.05
}

(Recepción: 30/05/2016. Evaluación: 10/10/2016. Aceptación: 7/12/2016. Publicación: 26/05/2017)

Resumen

La publicación mensual Teresa, Revista para Todas las Mujeres, fue la más duradera y la más leída de todas las revistas de la Sección Femenina. Funcionó como el órgano oficial de la organización de mujeres falangistas durante los años 1954-1977, una etapa marcada por los profundos cambios políticos, económicos y sociales en la dictadura de Franco. Sus artículos, entrevistas e imágenes constituyen un esfuerzo de construcción identitaria para una mujer joven, urbana y de clase media, como

1 Este artículo forma parte del proyecto de investigación «Discursos e identidades de género en las culturas políticas de la derecha española, 1875-1975» (HAR201232539), del Ministerio de Economía y Competitividad. 
parte de un proyecto más amplio dirigido a obtener una audiencia capaz de identificarse con sus propuestas de feminidad falangista. El artículo analiza las relaciones entre género y clase en la retórica de la Sección Femenina que sentaron las bases del discurso y los modelos de activismo en las organizaciones conservadoras de mujeres durante la transición española a la democracia. La hipótesis es que durante la segunda mitad de los años sesenta, los asuntos relacionados con el género fueron priorizados de manera diferente dentro de la agenda política de las mujeres de derechas, en buena medida gracias a la creación y utilización pragmática de diferencias de clase. El artículo pretende analizar los factores de estos realineamientos de clase y género, examinando específicamente cómo los escritores y editores de Teresa describían y definían el lugar de la mujer en dos espacios: el espacio del hogar y la vida familiar, y el espacio del lugar de trabajo y de la vida profesional.

\title{
Palabras clave
}

Sección femenina de la Falange; régimen franquista; género; clase; Teresa.

\begin{abstract}
Of all the journals published by the Sección Femenina the monthly Teresa, Revista para Todas las Mujeres, was the most read and the one published for the longest period. It functioned as the official mouthpiece of falangist women between the years 1954-1977, a period in the life of the Franco dictatorship marked by profound political, economic and social changes. The articles, interviews and images published in Teresa constitute a conscious effort to fashion the identity of young, urban middle class women. This effort was part of a large project aimed at creating an audience capable of identifying with the messages and images of falangist womanhood. The article analyses the relationship between gender and class in the Sección Femenina's discourse and practices as a conservative women's organization during the final years of the dictatorship and the transition to democracy. Our hypothesis is that during the second half of the 1960s gender issues were prioritized differently within the political agenda of right — wing women's organizations. This was achieved partly through the manipulation of the concept of class and of class differences. The article analyses these changes by focusing on the ways in which the writers in Teresa described and defined the role of women within two spaces: the space of the home and of family life and the space of work and of professional life.
\end{abstract}

\section{Keywords}

Sección Femenina of the Falange; Franco Regime; gender; class; Teresa. 


\section{SUMARIO}

I. INTRODUCCIÓN. II. TERESA: EL PERFIL DE UNA REVISTA, SUS ESCRITORES Y SU AUDIENCIA. III. LA MUJER Y SU HOGAR: FORJANDO UN SENTIDO DE PROPÓSITO Y PERTENENCIA ANTE DIFERENCIAS DE GÉNERO Y GENERACIONALES. IV. LAS MUJERES Y EL ESPACIO DEL TRABAJO: LAS JERARQUÍAS DE PLENITUD PROFESIONAL. V. CONCLUSIONES. BIBLIOGRAFÍA.

\section{INTRODUCCIÓN}

Estoy convencida de que lo que más determina al ser humano es el sexo, y siempre tengo presente que el hombre es diferente a la mujer. Eso es irreversible, es de naturaleza. Por eso todos los movimientos en pro de la mujer que tienden a una identidad total de la mujer con el hombre, son desequilibrados. La mujer es diferente al varón, pero no debe serlo ante la sociedad y sus estructuras juridicas y sociales ${ }^{2}$.

Ninguna militante ni dirigente de la Sección Femenina se negó a cumplir los ideales que difundian. Entre nosotras habia tantos matrimonios, idilios y amorios, correspondidos o no, como en cualquier otro sector de la vida femenina. Lo que no habia, por supuesto, era ese matrimonio-recurso en el que tantas veces, en aquellos tiempos, caian muchas mujeres por aburrimiento de una vida monótona. Por motivos económicos o por aquel ridículo prejuicio de no "quedarse para vestir santos», cumpliéndose muchas veces la copla flamenca: "No te quiero más castigo, que estés durmiendo con otro, y estés soñando conmigo».

Las citas anteriores han sido extraídas de entrevistas realizadas a dos militantes de alto rango de la Sección Femenina de la Falange Española Tradicionalista (en adelante SF): Belén Landáburu y Elisa de Lara. Landáburu, abogada de profesión, fue miembro de las Cortes franquistas y del Senado de España desde 1977. De Lara — periodista, escritora y miembro vitalicia de la SF — fue durante años regidora central de Cultura de la Delegación Nacional de dicha institución. Las entrevistas se realizaron en 1972 y 1981, respectivamente, y

2 Belén Landáburu en una entrevista con Pilar Cernuda, Pueblo, 1-10-1972, citada en De Diego González (2008): 119.

3 Elisa de Lara, en una entrevista con Sara Palacio, «El punto de vista de la SF: la historia nos ha traicionado» (Madrid, 1981), p. 19. Disponible en: http://gredos.usal.es/ jspui/bitstream/10366/24792/3/THVII N83 P16-23.pdf 
apuntan directamente al diálogo complejo que las militantes de la SF mantenían en su intento de definir su identidad como mujeres nacionalistas, católicas y públicamente activas ante los enormes cambios sociopolíticos que experimentó la sociedad española en las décadas de los sesenta y los setenta.

La SF se fundó en junio de 1934. Durante sus 43 años de existencia fue dirigida por Pilar Primo de Rivera (hija del dictador Miguel Primo de Rivera y hermana del fundador de la Falange, José Antonio Primo de Rivera) ${ }^{4}$. En su momento de mayor apogeo, tras la Guerra Civil española, la organización alcanzó más de 600000 militantes. No hay duda de que durante las dos primeras décadas de la Dictadura de Franco, a través de su control de distintas organizaciones como el Sindicato Español Universitario, los sindicatos de enfermeras y profesoras y el Servicio Social para la Mujer, la SF tuvo un papel clave en la producción de lo que la historiadora Ángela Cenarro definió como la cultura política del falangismo: «Un conjunto de normas, creencias y valores que marcan la pauta para la acción, así como la utilización de estos referentes para la construcción de identidades colectivas con capacidad para sostener un proyecto político (o varios), una memoria de grupo o un conjunto de estrategias de actuación"s.

En el caso de las mujeres españoles, como señaló acertadamente Inmaculada Blasco Herranz, el Estado franquista:

[...] emitió una llamada explícita [...] para que se implicaran en la construcción del mismo. Para ello apeló a una misma identidad nacional, homogénea, monolítica y basada en la noción de servicio a la patria y a la religión, aunque articuló una versión distinta de dicha identidad para las mujeres: su servicio a la patria y a la religión había de desplegarse, no en el trabajo extradoméstico, ni en la participación política, de los que fueron excluidas, sino en su destino de maternidad y socialización en la familia, terrenos estos que, además, se habían convertido en asuntos de interés público (en tanto que cuestiones de preocupación nacional) y susceptibles de intervención estatal ${ }^{6}$.

El intento de llevar a la práctica el mito de una «Nueva España», condujo al Estado franquista a intervenir en cada uno de los aspectos de la vida

4 Para otros trabajos sobre la SF y sus políticas durante el régimen de Franco, véase Gallego (1983); Blasco Herranz (1999); Palomares Ibáñez, (2001): 91-100; Bergès (2003); Rodríguez López (2004); Cenarro (2006); Rabazas y Ramos (2006), y Morcillo (2010).

5 Cenarro (2013): 199-200.

6 Blasco Herranz (2005): 57. 
cotidiana de la mujer española y de la familia, transmitiendo a través de ellas los valores y normas que el régimen definió como base de su doctrina. Pero fue precisamente el carácter exhaustivo de la extensa plantificación social y demográfica de ese proyecto el que abrió un espacio para la actuación de algunas mujeres dentro de lo que Roger Griffin identificó como el «Estado jardinero» totalitario 7 . Sin embargo, a mediados de los años sesenta, el control que ejercía la SF sobre determinados sectores de la tecnocracia estatal y sobre las vidas de las mujeres españolas se estaba debilitando, ya que el número de afiliadas se redujo radicalmente y surgieron oportunidades alternativas de asociación para mujeres.

Este artículo es parte de un proyecto de mayor envergadura que analiza los discursos y las pautas cambiantes del activismo de las organizaciones femeninas conservadoras durante los últimos años del franquismo y la Transición española. En este artículo, utilizo el prisma de la revista Teresa para explorar la relación que la SF mantenía con sus puntos de referencia ideológicos durante los años sessenta y setenta ${ }^{8}$. Quiero examinar específicamente cómo los escritores y editores de Teresa utilizaban las nociones de género, clase y generación para describir y definir el lugar de las mujeres en dos espacios: el espacio del hogar y la vida familiar, y el espacio del lugar de trabajo y de la vida profesional.

Desde su fundación, el discurso de género de la SF se basó en percepciones conservadoras sobre la adecuada división de roles y responsabilidades entre hombres y mujeres. Sin embargo, tal y como indico en otro lugar, las prácticas políticas y sociales que formaban parte de la vida cotidiana de las militantes de la SF reflejaban una combinación de elementos de modernidad y conservadurismo que no iban de la mano con el discurso de la organización?. Algunos historiadores, al reconocer esta contradicción, intentaron explicarla de dos formas diferentes. Unos afirmaron que los aspectos progresistas de la retórica y la praxis de la SF se habían formulado en los años sesenta

\footnotetext{
Griffin (2010).
}

8 En este contexto véase también: Muñoz Sánchez (2006): 118-128.

9 Hago mía la definición de Roger Griffin, que distingue entre la modernización como un "conjunto de procesos de la sociedad occidental desencadenados por una serie de cambios ideológicos, políticos, culturales, sociológicos, institucionales y tecnológicos [ ] y la modernidad, que denota los efectos (tanto objetivos como subjetivos) producidos por las fuerzas modernizadoras». Entre los efectos característicos de la modernidad, Griffin menciona la progresiva secularización de la vida humana, la erosión de la cosmovisión y del sistema de valores tradicionales y la transformación radical de la vida material de las personas (Griffin, 2010: 72). Véase también: Ofer (2009a). 
como resultado de la liberalización general que experimentó la sociedad española en la época. Para ellos, la imagen de los años sesenta presentaba un cambio evidente respecto al discurso de las dos décadas anteriores ${ }^{10}$. La historiadora francesa Marie-Aline Barrachina, que distinguía entre lo que ella definía como el «ideal de la mujer falangista» y el «ideal falangista de la mujer», presentó una segunda línea de explicación. A la primera categoría pertenecían las miembros de la jerarquía nacional de la SF: cultas y activas donde eran necesarias, ya fuera en el frente o en el ámbito político. A la segunda categoría pertenecía el resto de la población femenina, cuyo objetivo asignado en la vida era criar una nueva generación de hombres nacionalsindicalistas. Barrachina afirmó que los elementos más "progresistas» del discurso de género de la SF estaban dirigidos estrictamente a sus propias militantes. Según sus palabras, esos elementos estaban ocultos tras la fachada de imágenes tradicionales de feminidad católica para no suscitar el antagonismo de algunos de los sectores más conservadores del régimen.

Mi afirmación, no obstante, es distinta. El discurso de género de la SF, desde sus principios, no se basaba en una concepción más igualitaria, sino en una visión orgánica de la sociedad. Dicha visión hacía uso de las nociones de jerarquía y función para justificar el trabajo y la movilización pública de las mujeres, mediante la construcción de unos «otros» (en términos de generación, género y clase), cuya mera existencia justificaba las pautas específicas del activismo por parte de los grupos femeninos. Esta táctica caracterizaba ya algunos de los escritos en las primeras publicaciones de la SF (como Medina). Sin embargo, para historizar el modelo de feminidad promocionado por la SF es necesario analizar no solo sus prácticas cambiantes, sino también las justificaciones que dieron al activismo femenino dentro y fuera del hogar.

Si durante los años cuarenta la organización intentó moderar las referencias a las tensiones sociales en términos de género, durante la segunda mitad de la década de los sesenta — debido a varias razones relacionadas con el crecimiento económico acelerado, las consecuencias del Concilio Vaticano II y la creciente repercusión de la escolarización femenina - las discusiones en torno al género, y en especial las tensiones relacionadas con esta categoría, no pudieron atenuarse ${ }^{11}$. Durante el mismo período, el equilibrio cambiante de las relaciones de clases influyó en la estructura organizativa y en los discursos colectivos de muchas organizaciones femeninas conservadoras. En el caso de la SF notamos una matización más que un giro discursivo, pues se trata de

10 CocaHernando (1998): 7.

11 Ofer (2009a): 58-67. 
una organización cuyo modelo íntegro de activismo político femenino dependía siempre de la explotación de las diferenciaciones de clase ${ }^{12}$.

Así que el discurso que se expresó a través de las páginas de Teresa reevaluó el papel y el lugar de las mujeres en el hogar, el lugar de trabajo y el espacio público en general ${ }^{13}$. Mediante la coordinación de varios artículos, entrevistas e imágenes gráficas, Teresa fue la manifestación de un esfuerzo consciente dirigido a construir una identidad para las mujeres jóvenes, urbanas y de clase media. La dirección nacional de la SF utilizó el formato supuestamente inofensivo de revista popular para afrontar los cambios sociales, demográficos y económicos y para evaluar los límites cambiantes entre lo "privado» y lo "público» ${ }^{14}$. Al mismo tiempo, sin una base popular sólida, pero deseando fomentar su posición definida como grupo de presión dentro del sistema político franquista, la SF trató de crear a través de Teresa una audiencia capaz de identificarse con su imagen de feminidad falangista. En este sentido los escritos que aparecían en la revista demostraban que las tensiones entre lo que podía considerarse una vocación femenina «tradicional» y la encarnación de la modernidad seguían presentes en las vidas de las militantes de la SF y no se habían resuelto con el paso del tiempo.

\section{TERESA: EL PERFIL DE UNA REVISTA, SUS ESCRITORES Y SU AUDIENCIA}

La revista Teresa se editó entre 1954 y 1977 y actuó como portavoz oficial de la SF durante dos décadas y media de profundos cambios políticos,

12 Desde los primeros días de la Guerra Civil, la SF basaba su llamada al activismo publico y político de algunos sectores femeninos (mujeres nacionalistas, educadas, de clase alta y media y la mayoría solteras) sobre una supuesta necesidad nacional de adoctrinar y «reeducar» a otros colectivos femeninos (constituidos por las vencidas de la Guerra Civil, mujeres «rojas», su mayoría de clase obrera, urbana y rural).

13 Ofer (2006).

14 Hay un importante desequilibrio en la literatura existente sobre la historia de las mujeres y las relaciones de género durante la Dictadura y la Transición. Mientras que durante las dos últimas décadas se ha publicado un número creciente de trabajos relacionados con el género y la historia de las mujeres durante la Dictadura, se ha escrito poco hasta ahora sobre la Transición.

Para otros trabajos sobre el franquismo, véase Nielfa Cristobal (2003); Blasco Herranz (2003); Morcillo (2000), y Moreno (2012).

Para otros trabajos sobre la Transición, véase, por ejemplo, Threlfall et al.(2005); Martínez Ten et al. (2009), y Mañas Viejo et al. (2015). 
económicos y sociales que se manifestaron en las protestas estudiantiles de 1956, pasando por la campaña para la aprobación de la Ley de Derechos Políticos, Profesionales y de Trabajo de la Mujer (1961), las huelgas industriales y el Concilio Vaticano II (1962-1965), el asesinato del almirante Luis Carrero Blanco (1973) y el fallecimiento del general Franco (1975). También, finalmente, la Transición española a la democracia y el desmantelamiento de la propia SF en 1977.

Elisa (Lula) de Lara dirigió desde el principio la revista mensual Teresa. De Lara, cuyos rasgos más notables eran su sentido del humor y su lengua afilada, tuvo una gran influencia en la elección de los escritores y artículos de la revista. Ejerció su influencia, principalmente a través de sus editoriales extremadamente críticos y cínicos, que aparecían bajo los titulares de "Teresa» y «Una carta para...». Junto a De Lara, el editor jefe de Teresa era Jesús de la Serna Gutiérrez-Répide, un periodista nacido en Santander que posteriormente se convirtió en editor de periódicos importantes como Pueblo, Informaciones y, en 1981, de El País. A lo largo de los años estuvieron acompañados por conocidas figuras del mundo de la literatura española y el periodismo de la época, como José Montero Alonso y José María Moreno Galván; intelectuales falangistas como Ernesto Giménez Caballero; y mujeres novelistas y periodistas como María Dolores Medio Estrada, Pilar Narvión Royo e Isabel Cajide.

Cada volumen de Teresa contenía alrededor de sesenta páginas tamaño A3. Cada mes, varias páginas se dedicaban a informar sobre las actividades de la SF y también se incluían citas de los escritos de José Antonio y de los discursos de Pilar Primo de Rivera. Cerca de una tercera parte de cada número se dedicaba a temas de moda, decoración del hogar y cocina. A pesar de que la propia De Lara declaró que «nosotras hemos dado siempre un contenido espiritual a todas las paginas y los temas. Eliminando sin piedad todo aquello que no se obedezca a este criterio", el material de naturaleza religiosa constituía, aproximadamente, solo el $5 \%$ de lo que se publicaba en Teresa ${ }^{15}$. Las columnas regulares informaban sobre la economía española y las fluctuaciones en el mercado laboral franquista. Una columna titulada "Las mujeres quieren trabajar» proporcionaba a la audiencia información sobre la disponibilidad de trabajos y oportunidades de formación profesional en los sectores público y privado. Otros artículos cubrían los acontecimientos internacionales y eventos culturales principalmente en Europa y los Estados Unidos, aunque también en Asia y Oriente Medio.

Muchos de los mensajes que aparecieron en las primeras publicaciones de la SF se abrieron camino en las páginas de Teresa. Entre ellos se encontraba la importancia de la educación superior para las mujeres, la consideración de las

15 «Nuestro criterio, así quiere ser Teresa», Teresa, núm. 25, enero 1956. 
carreras femeninas como vocación o la contribución única de las mujeres a la vida pública española a través de un mayor activismo. Estos temas tenían una relevancia especial en vista de la audiencia a la que se dirigía Teresa. La experta en medios de comunicación Megan Le Masurier hace referencia a la relación única entre las revistas y su audiencia, que las distingue de otras formas de publicación populares:

La audiencia de una revista no es un "público» amorfo. La audiencia de una revista tiene intereses específicos que el editor y el personal ignoran bajo su cuenta y riesgo. Esta consideración de una audiencia nicho tiene como resultado una relación más personal con el lector. Explica también el tono de varias revistas: «Una extraña zona fronteriza [...] en algún lugar entre la conversación y la escritura, entre lo público y lo privado» ${ }^{16}$.

En el caso de Teresa, definir la identidad de la audiencia a la que se dirigía no fue una tarea directa. En el último número de la revista, que se publicó en julio de 1977, Elisa de Lara escribió:

Con este número Teresa termina su vida, que inició en enero 1954 con la esperanza y el deseo de convertirse en la compañera de todas las mujeres españolas [...]. En estos 23 años nuestra revista ha procurado efectivamente huir de todo lo chirriante y rabioso y su tónica ha sido servir a mujeres normales, con problemas normales y gustos normales también; procurando siempre que toda esa normalidad se viera tratada en sus páginas con alturaliterariay de especialización $[\ldots]^{17}$.

Si leemos este fragmento considerando el contenido de la editorial que lanzó el primer número de Teresa en 1954, quizás podemos entender mejor quienes fueron esas mujeres «normales». En enero de 1954 De Lara escribió:

Teresa echa a andar como echa a andar siempre Teresa. Con resolución y a lo que sea. A la antigua pero motorizada. Teresa, que anduvo por el ancho mundo en borriquillo, anda ahora en Vespa, habla un poco de inglés, fuma y nada, porque eso no es pecado [...]. El ancho mundo de Teresa es ahora medio planeta. Teresa está muy bien criada, sabe muy bien dónde está el pecado y dónde está la virtud, y cree que si la gloria de Dios puede andar entre los pucheros, ¿por qué no va a andar en un instituto de belleza? ¿Entre potes de cremas? Se librará muy bien de la frivolidad pura, pero se liberará también de la gazmoñería pura. Duchada,

16 Le Masurier (2014).

17 «Editorial», Teresa, núm. 282, julio 1977. 
perfumada, aligerada, con su melena negra al viento, azafata de la ilusión de España, con un parvo equipaje de libros de oración, revistas de moda, make-up y ropa interior de seda, coraza de fe y clara lengua ${ }^{18}$.

Perfumada, bien vestida, motorizada y fumadora, consumidora de revistas de moda, literatura (española y extranjera) y libros de oraciones... Teresa daba la imagen de una "nueva mujer» que no existía necesariamente en la España de 1954. Sin embargo, era, sin duda, la imagen de cómo la SF quería moldear a las mujeres. Era también la imagen de mujeres a las que la sociedad española se acostumbraría cada vez más a medida que el "milagro» económico de la década de los sesenta y la progresiva apertura de la sociedad española a influencias externas (a través del turismo y la cooperación internacional) se convertían en una realidad. Algunos elementos de esta imagen de feminidad falangista moderna fueron aceptados por el régimen de Franco, que dos décadas después del final de la Guerra Civil dejó de equiparar a las amas de casa españolas con la austeridad y comenzó a equipararlas con el consumismo. Sin embargo, el intento de presentar el consumo como una obligación nacional más - junto con la maternidad — también generó tensiones, ya que la SF utilizó el consumo — de la misma forma que utilizó la maternidad — como una obligación y una plataforma desde la que lanzar ciertas formas de activismo público.

Al mismo tiempo, es importante recordar que las ayudas materiales que De Lara utilizó para representar a Teresa también definían a la población femenina que estaba lejos de identificarse con esta imagen. Maquillaje, ropa de temporada a medida y motocicletas eran cosas con las que las decenas de miles de mujeres que apenas llegaban a fin de mes en las zonas rurales de España, o aquellas que se desplazaban a los barrios chabolistas autoconstruidos en las afueras de las principales ciudades españolas, solo podían soñar. Bajo la hábil gestión de Elisa de Lara y Jesús de la Serna, surgió una filosofía editorial que tuvo en cuenta los deseos, las preocupaciones y la realidad del día a día de una audiencia femenina muy específica, así como las restricciones políticas y sociales bajo las que se publicaba la revista.

\section{LA MUJER Y SU HOGAR: FORJANDO UN SENTIDO DE PROPÓSITO Y PERTENENCIA ANTE DIFERENCIAS DE GÉNERO Y GENERACIONALES}

Mientras que la retórica de la SF repetía una y otra vez su afirmación de que el hogar de una familia era un lugar que debía ser moldeado y controlado

18 «Una carta abierta», Teresa, núm. 1, enero 1954. 
por mujeres, la legislación española durante la Dictadura establecía que las mujeres solo podían controlar aspectos limitados de su vida familiar. El artículo 1882 de la Ley Española de Enjuiciamiento Civil definía claramente el hogar familiar como propiedad del marido (casa del marido). El artículo daba libertad al marido para hacer lo que quisiera con la propiedad familiar y privaba a las mujeres que solicitaban la separación legal "por causas justificadas» del derecho de seguir viviendo allí. Las mujeres casadas también necesitaban obtener el permiso de sus maridos para asumir obligaciones legales vinculantes: solicitar un trabajo, participar en procedimientos legales, aceptar o rechazar herencias, o actuar como albacea. De hecho, de acuerdo a esas condiciones, las mujeres no podían ser dueñas del espacio que el propio régimen definía como suyo. Su capacidad para moldearlo de acuerdo a sus necesidades desde una perspectiva económica, material y emocional- dependía de la aprobación de sus maridos.

Frente a esta realidad, Mercedes Formica Corsi (abogada y antigua miembro fundadora de la SF) lanzó en 1958 una campaña que tuvo como resultado la enmienda parcial del Código Civil español ${ }^{19}$. En una serie de artículos que se publicaron entre 1954 y 1957, Formica utilizó a Teresa como una plataforma de debate e intentó presentar estrategias que asegurarían que las mujeres pudieran actuar como individuos independientes dentro de la unidad familiar. Recurrió a las propias mujeres y a sus padres y madres para que aceptaran la responsabilidad de su bienestar. Formica advirtió de una situación en la que el $90 \%$ de los acuerdos prenupciales no proporcionaban una división equitativa de los bienes familiares y dejaban a la mujer sin apoyo económico en caso de separación. Además, también le inquietaba que las familias españolas se esforzaran por lograr que sus hijas llegaran al matrimonio con una salud perfecta, mientras que nadie las protegía de sufrir abusos físicos una vez que estaban casadas ${ }^{20}$.

Reformar la legislación existente era una forma de proporcionar a las mujeres más control sobre sus propias vidas. Sin embargo, la legislación por sí sola no podía cambiar las pautas de comportamiento tradicionales en el seno de las familias españolas. Por ejemplo, Elsa Constantina Velásquez Zamudio instó a las mujeres (a las que siempre se les decía que su papel era criar y educar a las futuras generaciones) a que utilizaran su propio poder para generar un cambio «más profundo»:

19 La reforma de 1958 incluía 66 artículos, la mayoría de los cuales estaban relacionados con la situación legal de las mujeres casadas.

20 M. Formica, «Vuestra misión de madres: crear un ambiente», Teresa, núm. 6, junio de 1954. 
Nosotras somos las principales causantes de la sub-estimación social a que estamos sometidas. Y lo que es mas sobrecogedor, somos agentes activas de la misma situación por cuanto desde nuestra invalorable posición de madres o de cualquiera otra posición dentro del hogar seguimos por rutina, por inconsciencia o por malicia educando a nuestros hijos o familiares con una dualidad moral inconcebible: una moral para la mujer y una moral para el hombre [...]. El hijo varón guarda privilegios inconcebibles dentro del hogar porque así lo determina la madre y todas las mujeres de la casa ${ }^{21}$.

En una sección titulada «La familia española», los editores de Teresa invitaban a los colaboradores a que sugirieran estrategias para mejorar la estabilidad de la vida familiar mediante la cooperación entre los sexos. La estabilidad ya no se quitaba ni se consideraba como responsabilidad únicamente de las mujeres. Enrique Warleta Fernández sugirió en la columna que parte del problema residía en la total falta de implicación de los padres españoles en la vida de sus hijos. Los padres tenían otras obligaciones aparte de simplemente proporcionar el bienestar económico de los hijos o disciplinarlos. Crear una relación emocional positiva con ellos — una relación que debía reflejarse en periodos diarios de juego y estudio en común — también era su responsabilidad ${ }^{22}$.

Si los padres y los hijos asumieran más tareas y responsabilidades de la vida doméstica, quizás las mujeres podrían disfrutar de su hogar como un lugar de descanso y relax, y no solo como un lugar de trabajo constante. Como señaló el columnista de "Hogar», en relación con el destino de las amas de casa durante las vacaciones de verano, era necesaria una aproximación racional a la vida familiar y una redistribución de las tareas existentes:

¿Bien descansado? Los hijos sí, pero ¿y la sufrida ama de casa? En el fondo, ¿qué es para ella llegar el verano? Un ama de casa también necesita descansar; si se me apura, lo necesita más que nadie, porque el trabajo de la casa, a la larga, resulta agotador. Por tanto, antes de comenzar las vacaciones reunid a vuestra familia y planteadle seriamente que ya está bien eso de que todos descansen menos vosotras. Y que la esclavitud la abolió Abraham Lincoln hace ya bastantes años ${ }^{23}$.

21 I. Velásquez Zamudio, «La protección de la unidad biosocial madre-hijo», Fundación Nueva Andadura (Real Academia de Historia), Asociación de Nueva Andadura (henceforth ANA), Serie Roja, Carp. 1057.

22 Warleta Fernández, «Rincón familiar: usted tiene otro oficio», Teresa, núm. 15, marzo de 1955.

23 «Hogar», Teresa, núm. 187, julio 1969. 
Hablando en términos generales, los editores de Teresa evitaron la crítica directa a los principios morales y religiosos del régimen. Este era el caso, especialmente, en temas relacionados con las relaciones de género. En cambio, los escritores elegían frecuentemente utilizar una dosis elevada de cinismo cuando describían la realidad — dejando que la audiencia sacara sus propias conclusiones- o construir figuras discursivas de "otros», hacia los que dirigían la culpa por el estado lamentable de la mujer española dentro de su propio hogar. Por ejemplo, en un artículo de 1955 escrito por Isabel Cajide (periodista y miembro de la SF), se presentaba a los hombres como un colectivo cuyas demandas eran tan ridículas que el único antídoto contra ellas era una sana dosis de cinismo:

No se puede formular una opinión de la mujer sin tener en cuenta las observaciones, y sobre todo las consecuencias de las observaciones, de los diferentes tipos humanos [...]. Los hombres que interfieran en esta entrevista nos han contestado con tanta agudeza que no hay más remedio que tomarlos muy en serio. Todos, excepto uno, opinan que la mujer debe trabajar únicamente en el hogar, y seguramente tienen razón. Lo peor es que para complacerles habría que realizar en la estructura social tantas reformas que no nos atrevemos a intentarlo. De todos modos agradecemos a los hombres este generoso empeño de dejarnos pasar la vida con más comodidad que ellos. ¡Lástima que las cosas se hayan puesto tan malas para nosotras! $!^{24}$

Los hombres, como colectivo, no constituyeron el único objeto de las críticas. En 1972, De Lara dirigió una "Carta abierta a la tía Mercedes», la hermana mayor de su abuela. La carta era uno de los muchos intentos de saldar las cuentas de su generación con una serie de madres y abuelas biológicas y espirituales. El texto dejaba claro que, a pesar de la liberación que había experimentado la sociedad española en los veinte años desde la publicación del primer número de Teresa, la capacidad de las mujeres para moverse libremente en un mundo masculino todavía se consideraba una «declaración de independencia» que no debía subestimarse:

¿Cómo iba a figurarme que un día sentiría la necesidad de charlar un rato contigo, la hermana mayor de mi abuela [...]? La culpa de todo la tiene esta revista italiana, una revista femenina, justo es reconocerlo, de prestigio [...]. Explica que en Madrid, una chica que resulta víctima de una ruptura de

24 I. Cajide, «El hombre en la calle opina sobre la mujer», Teresa, núm. 39, marzo 1957. 
relaciones queda poco menos que deshonrada. Vaya, ¡poco más o menos como yo quedé a tus ojos aquel día en que me sorprendiste a la salida de El Águila en donde había estado sola! Bebiéndome una doble cerveza. Qué habría dicho la gente, me preguntaste en un tono terrible. Y resulta que la gente no había dicho nada.

¿Puede suceder tal cosa en 1972, cuando hasta el Código Civil, que era vuestro mejor aliado, esta decidido a reconocer que no somos retrasadas mentales, que podemos ser del todo mayores de edad a los 21 años, como cualquier varón? ${ }^{25}$

Por lo tanto, colaboradores y redactores como De Lara se opusieron firmemente a las estrategias que relegaban a las mujeres a espacios específicos y les animaron a entrar en los mundos del trabajo, del ocio, de la producción cultural y de los viajes. Además, señalaron que el progreso de las mujeres en estas áreas podría verse gravemente entorpecido por la falta de tiempo y por el hecho de que no eran admitidas en los espacios en los que realmente tenía lugar la socialización profesional y la producción cultural. No obstante, los redactores de Teresa fueron incapaces de rechazar totalmente las justificaciones detrás de las restrictivas prácticas espaciales del régimen. La novelista Dolores Medio expresó mejor esta ambivalencia cuando fue entrevistada en el primer número de Teresa:

A lo largo de todo este tiempo último la mujer ha ido demostrando su capacidad para toda suerte de trabajos. Tras de haber trabajado por ejemplo en las industrias de guerra, ¿qué podría razonablemente negársele en este sentido por el hombre? Y sin embargo, a pesar de todo, y reconociendo esa plenitud con que la mujer puede hoy trabajar en muchas cosas que antes se le negaban, creo que ella debe conservar lo que acaso está en riesgo de perder y era su arma mejor — su debilidad aparente-. Necesita conservar esta por encima de todo. Somos débiles mas en esto, paradójicamente, está nuestra fortaleza.

Yo creo que esa ausencia de la mujer en determinadas actividades — la arquitectura, la ingeniería - no es debida a falta de aptitud para ello, sino el peso de mucho tiempo alejada de toda actividad, entregada a un tipo único de vida. Solo una (limitación), impuesta por la misma condición de la mujer: la maternidad. La casa ha de ser de la mujer siempre. Esto ha de ser salvaguardado a toda costa ${ }^{26}$.

25 «Carta abierta a tía Mercedes, la más retrógrada de la familia», Teresa, núm. 224, agosto de 1972.

26 J. Montero Alonso, «Dolores Medio opina: El problema de hoy, feminismo y antifeminismo», Teresa, núm. 1, enero 1954. 
Las formas en las que los escritores de Teresa trataron la discusión sobre la ley de divorcio (que el Parlamento italiano debatió y aprobó en 1968) y sobre el uso de anticonceptivos (tras la publicación de Humanae Vitae por el papa Pablo VI el 25 de julio de 1968) reflejaban los límites de la plenitud personal y emocional que las mujeres podían esperar. En un artículo que apareció en abril de 1967, María Pilar Hernando informaba sobre el debate existente en la prensa italiana en relación con la legislación sobre el divorcio. Declaró, inequívocamente: «Nosotros pensamos que constituye una ventaja moral y un signo de civilización superior para un pueblo mantener estable, intacta y sagrada la institución familiar ${ }^{27}$. En una »Carta abierta a la baronesa de Summerskills», Elisa de Lara escribió diez meses después:

Sí, tiene mala cara la familia: se le ve en la crisis de la autoridad paterna, en los hijos rebeldes por capricho, hasta en ese silencio que la breve pantalla de TV ha venido a crear en su seno [...]. Pero, ¿cuál es la enfermedad?

Sin embargo, la ley del hombre inventó el divorcio. ¿Es que si se fracasa en el matrimonio va a haber que soportarlo toda la vida? La verdad es que humanamente no es fácil aceptarlo. Tampoco es humanamente fácil amar un enemigo, ni respetar los bienes del prójimo. No es fácil, pero en cambio es lo mejor. Tiene su explicación. El hombre vive de tejas abajo, Dios de tejas arriba ¿̨no es natural que sea mucho más completa su perspectiva? ${ }^{28}$

Como puede observarse aquí, para describir y definir lo que podría considerarse una familia equilibrada y que propiciaba la crianza y un hogar que funciona satisfactoriamente, los escritores y editores de Teresa utilizaban una selección de entrevistas, investigaciones y editoriales, así como secciones especiales dedicadas a la gestión y diseño del hogar. Una familia que funcionaba se definía menos en términos de jerarquía y más en términos de funciones asignadas, con un énfasis creciente en la calidad de las comunicaciones entre diferentes miembros de la familia y las capacidades de crianza de ambos padres. El hogar seguía percibiéndose principalmente como el dominio de las mujeres. Sin embargo, se prestaba mucha atención a las condiciones que proporcionarían a las mujeres el control real del espacio de la vida familiar (mediante la legislación, presupuestos independientes y el acceso a la información) y que podrían hacer del hogar un lugar en el que relajarse y disfrutar (principalmente mediante una nueva división del trabajo y las obligaciones). Dado que estas condiciones se lograrían solo parcialmente y de forma gradual

27 «¿Qué piensa usted sobre el divorcio?», Teresa, núm. 160, abril 1967.

28 «Carta abierta a la baronesa de Summerskills», Teresa, núm. 170, febrero 1968. 
durante las décadas de los sesenta y los setenta, muchas de las referencias al hogar «ideal» también incluían referencias a «otros», que a través de sus prejuicios y su mala conducta todavía impedían que las mujeres guiaran la vida familiar en la dirección adecuada: principalmente hombres y mujeres de generaciones anteriores. Desde el punto de vista de los escritores de Teresa, mientras esos "otros» podían ser ridiculizados sutilmente y su visión de la vida familiar podía modificarse, la familia seguía considerándose una entidad sagrada que no podía romperse ni alterarse. Las mujeres podían elegir evitar la maternidad y el matrimonio completamente pero, si elegían crear una familia, debían aceptar el "principio de acumulación», según el cual se les exigía ser perfectas esposas y madres y, únicamente tras lograrlo, podían alcanzar la plenitud profesional o social ${ }^{29}$.

\section{LAS MUJERES Y EL ESPACIO DEL TRABAJO: LAS JERARQUÍAS DE PLENITUD PROFESIONAL}

Inmediatamente después de la Guerra Civil, las autoridades franquistas también actuaron para cambiar la situación legal de las mujeres dentro del mercado laboral. No solo estaba prohibido que las mujeres casadas firmaran contratos de trabajo de forma independiente, pues una ley de 1946 forzaba a las mujeres que ya trabajaban a que solicitaran una excedencia forzosa tras su matrimonio $^{30}$. Otra ley de 1957 las excluía de todos los lugares de trabajo "peligrosos» $\mathrm{o}$ "con riesgo moral " $^{31}$. Los salarios de las mujeres eran considerablemente más bajos que los de los hombres y aquellas que trabajaban no tenían derecho a recibir pagos por horas extraordinarias.

A pesar de esta legislación discriminatoria, la historiadora española Cristina Borderías ha mostrado que en el periodo comprendido entre 1940 y 1960 tuvo lugar el aumento más significativo en el número de mujeres contratadas remuneradas en España ${ }^{32}$. En 1940, el porcentaje era de un 8,8 \% y en 1960 la cifra se había doblado, alcanzando un 15,13\%. Mientras que en 1950 las mujeres suponían el $23 \%$ de la población trabajadora española, en 1960 su presencia aumentó hasta un $28 \%$. Evidentemente, estas cifras no reflejan el elevado número de mujeres que trabajaban en el campo y en el hogar sin estar registradas oficialmente como trabajadoras.

\footnotetext{
29 Sobre el tema de la soltería en el seno de la SF, véase Ofer (2009b): 43-50.

30 Orden del Ministerio de Trabajo de 27 de Julio de 1946.

31 Basora Francesch (1964):126-127.

32 Borderías (1993): 22 y 35.
} 
En 1951 Pilar Primo de Rivera pidió a Mercedes Formica que realizara un informe general sobre el trabajo de las mujeres en España y que enumerara las reformas necesarias para mejorar la situación. Formica reunió un equipo de once mujeres, pero el documento que produjeron, y que debía presentarse en el Congreso Internacional Femenino Hispanoamericano de 1951, nunca fue publicado ${ }^{33}$. No obstante, sin el conocimiento de Mercedes Formica, el contenido del informe se utilizó al año siguiente en una serie de documentos de posición recopilados por la SF y destinados a la Dirección Nacional de Trabajo ${ }^{34}$. También sirvió como base para algunas secciones de la Ley sobre Derechos Políticos, Profesionales y de Trabajo de la Mujer ${ }^{35}$.

Desde su primer año de publicación Teresa funcionó como portavoz oficial de la SF, preparando el camino para el cambio legislativo de $1961 \mathrm{y}$ siguiendo su implementación en distintos ámbitos laborales y judiciales. Un año después de la publicación del primer número, los editores de Teresa lanzaron una nueva columna titulada «Las mujeres quieren trabajar». La primera columna afirmaba:

Teresa, siguiendo la iniciativa de la Comisaria de Protección Escolar, ha decidido crear una nueva sección que sirva para orientar las vocaciones femeninas. La iniciaremos dando un esquema de las carreras universitarias que pueden cursar las mujeres españolas y de algunas profesiones que pueden elegir las que hayan concluido sus estudios [...]. Con este servicio creemos ayudar en nuestra medida a la urgente necesidad de que las mujeres toman conciencia de su propia misión ya que en cada una de las promociones que estarán en el ejercicio

33 Formica (1991): 36-37. Entrevista con Mercedes Formica, Richmond (2003): 87-88 y 155.

34 Para consultar el informe completo de Pilar Primo de Rivera ante la Junta de Regidoras Centrales de la SF, véase ANA, Serie Azul, Carp. 77, Doc. 21.

35 Esta ley incluía únicamente cinco artículos y el primero de ellos abolía «cualquier limitación de los derechos políticos, profesionales o laborales de la mujer excepto aquellos establecidos por la presente ley». Los artículos 2 y 3 de la nueva Ley de 1961 estipulaban explícitamente que las mujeres podían votar y ser elegidas para cualquier puesto público, incluyendo puestos en las administraciones estatales y locales, y que debían tener libre acceso a todos los niveles de educación. El artículo 4 también establecía el derecho de todas las mujeres a firmar contratos de trabajo de forma independiente. El artículo final establecía que en casos en los que todavía era necesaria la aprobación marital, una mujer a la que se le denegara dicha aprobación, podía demandar a su marido en los tribunales. Para un análisis más detallado de estos textos, véase: Ofer (2009a): 79-103. 
profesional la mujer debe encontrar el puesto que le correspondía y sin traicionar su propio destino $[\ldots]^{36}$.

La propia Elisa de Lara aclaró que el trabajo podía y tenía que ser más que una necesidad económica. En mayo de 1954, De Lara compartió con su audiencia — parte en broma y en parte en serio — su deseo de ser considerada «uno de los chicos» en el mundo del periodismo español. En el nombre de Teresa, escribió sobre el deseo desesperado de entrar en el mundo de las tertulias - aquellas reuniones sociales intelectuales que caracterizaban la vida intelectual española_- Las mujeres nunca tuvieron un acceso fácil a este mundo, y fueron excluidas casi totalmente de él en los años posteriores a 1939. De Lara escribió:

Hoy [...] Teresa no puede ocultar por el júbilo que le ha producido. Teresa amigas, se ha visto sorprendida como protagonista de un homenaje. En él, los jóvenes periodistas — agrupados en la Asociación de Antiguos Alumnos de la Escuela de Periodismo- presididos por el director general, don Juan Aparicio, han piropeado de lo lindo a quienes hacen esta Revista. A Teresa se le ha ofrecido un "café de redacción", que es una cosa muy seria. Teresa es joven y por ello valora en toda su importancia el torrente de elogios que estos muchachos le regalaron aquella tarde, frente a los vasos de café, en el club de prensa de Madrid $^{37}$.

En 1961, las Cortes españolas aprobaron la Ley sobre Derechos Políticos, Profesionales y de Trabajo de la Mujer, defendida por Pilar Primo de Rivera. Durante el debate parlamentario que llevó a la aprobación de la Ley de 1961, los colaboradores de Teresa analizaron, en innumerables artículos, la posición de inferioridad de la mujer en el mercado laboral y afirmaron que los humildes logros profesionales y educativos de las mujeres no eran resultado de una inferioridad inherente, sino de cientos de años de discriminación. Algunos autores llegaron incluso a afirmar que la superioridad de los hombres en el mercado laboral y académico les permitía institucionalizar pautas de trabajo agresivas y competitivas que dificultaban la integración de las mujeres, que supuestamente tendían hacia la cooperación y el apoyo mutuo ${ }^{38}$.

36 «Las mujeres quieren trabajar», Teresa, núm. 23, noviembre 1955.

37 Teresa, núm. 5, mayo de 1954.

38 Véase, por ejemplo: «Las mujeres quieren trabajar: Las mujeres en las profesiones intelectuales», Teresa, núm. 24, diciembre de 1954; «Mujeres que trabajan», Ibid., 
En un nivel discursivo, y como introducción a la campaña para mejorar la imagen de la mujer trabajadora, algunos escritores insistieron en el papel de la palabra oral y escrita para dar forma a la realidad y criticaron la forma chovinista en la que muchos españoles utilizaban el lenguaje. En un artículo publicado en 1960 bajo el titular «Piensa, escribe y habla bien» se pregunta:

¿Debe decirse médico o médica a la mujer licenciada o doctorada en medicina y con autorización legal para ejercer? Desde luego la feminización de los apelativos de oficios o profesiones está conforme con las normas del idioma. En cambio el Diccionario de la Academia no trae la feminización de otros apelativos profesionales como ingeniero, arquitecto, juez, fiscal [...]. Quizá porque se trata de profesiones donde la mujer no ha logrado todavía penetrar de una manera generalizada [...]. Todo es cuestión de hábito idiomático. El tiempo tiene mucho que ver en este problema del lenguaje vivo [...]. Quien en última instancia decidirá no es la Academia sino el pueblo con el uso o desuso que le dé a esos vocabularios de profesionalidad ${ }^{39}$.

Cuando las Cortes españolas aprobaron la Ley sobre Derechos Políticos, Profesionales y de Trabajo de la Mujer, Pilar Primo de Rivera describió las prioridades de la SF en relación con su implementación en el Congreso Nacional de la organización de 1962:

Atención especial al sector llamando aprendices [...], a todas las productoras menores de 16 años. Revisión de la legislación vigente que afecta a las mismas para que de una manera más eficaz las ampare laboral y socialmente.

Que se procede rápidamente al replanteamiento de la formación profesional femenina que comprenda una valoración de los oficios femeninos, mediante unas enseñanzas y exigencias de titulaciones, clasificando las profesiones por las necesidades urgentes y menos urgentes del país por el contingente de mujeres $[\ldots]$.

Considerando en la SF que la enseñanza primaria es la base más importante para elevar el nivel cultural de un pueblo, entendemos que debe dársele la máxima dignidad y valoración social al magisterio [...].

Como complemento de la política estatal de protección a la familia que se estudie la necesidad de valorar social y económicamente el trabajo doméstico de la

núm. 97, enero de 1962; «Carta abierta a veinte mil familias», Ibid., núm. 150, junio de 1966.

39 «Piensa, escribe y habla bien: ¿Doctora o doctor?», Teresa, núm. 77, abril de 1960. 
mujer casada. Necesidad de regular nuestras relaciones con los sindicatos para el contacto y atención de la mujer trabajadora ${ }^{40}$.

Como se desprende de la cita anterior, la campaña para lograr los derechos políticos y profesionales de la mujer proporcionó a la SF un importante impulso organizativo. A partir de 1961, el Departamento de Asesoría Jurídica de la SF se sobrecargó con peticiones de mujeres que deseaban ver la implementación de la nueva legislación, pero que no estaban conectadas de ninguna forma con la organización y sus instituciones. La ley también generó un interés renovado en carreras y programas de formación que ofrecían las instituciones de la SF (como las escuelas de especialidades: Julio Ruiz de Alda de Madrid y Roger de Lauria de Barcelona). Los programas de formación de profesoras de educación física, enfermeras, monitoras, etc., duraban entre dos y tres años. Estos programas estaban abiertos a mujeres jóvenes que no buscaban obtener un título universitario, pero habían completado el bachillerato superior o normal.

No obstante, la información proporcionada en relación con estas profesiones expuso, una vez más, la actitud paternalista de la SF sobre las mujeres del ámbito rural y la clase trabajadora. Reflejaba las formas en las que la organización utilizaba sus plataformas educativas para avanzar en el adoctrinamiento falangista y para crear oportunidades para la promoción profesional de sus propios miembros y de aquellas mujeres «normales» a las que Teresa consideraba su audiencia. La visión paternalista, que sujetó el ideal de igualdad de género a las restricciones ideológicas y de clase, fue especialmente clara en las referencias de la SF al SUT (el Servicio Universitario de Trabajo). El Servicio, creado en 1950 por el cura jesuita (y falangista) José María Llanos, estaba destinado a proporcionar a los estudiantes universitarios la posibilidad de que se «acercaran a los hombres que trabajan en el campo y en la industria». Un artículo que apareció en Teresa en 1965 seguía a estudiantes que querían pasar los meses de verano en las zonas rurales de Cuenca trabajando y viviendo junto a la comunidad local. Aurora Domínguez (licenciada en Filosofía y Letras por la Universidad de Sevilla), cuando se le preguntó la razón por la que se había unido al SUT, respondió:

El año pasado estuve en un campo de trabajo, en la provincia de Jaén. Como la labor de las misiones es más directa, he preferido incorporarme a ella [...]. En el campo de trabajo se convive con las obreras que trabajan en la industria, pero

40 P. Primo de Rivera, "Conclusiones del XXI Consejo Nacional de la SF", Teresa, núm. 98, febrero 1962. 
esta convivencia se limita a las horas de trabajo. En las misiones vivimos en las casas y durante todo el día estamos con ellos. Además damos clases y nos ocupamos de ayudar en las casas ${ }^{41}$.

Ángeles Rodríguez (estudiante de medicina en la Universidad de Granada) añadió: «Entre la gente del campo hay un concepto erróneo de lo que es un estudiante. Por deshacer este error. Y porque deseo ayudar a la gente que lo necesita». A María Teresa García Alba (estudiante de Derecho en Barcelona), la entrevistadora le preguntó si no tenía miedo y esta, tras responder negativamente, enumeró los resultados de su trabajo en Andalucía el año anterior: «Excelentes. Piensa que estas gentes no tienen durante todo el año más convivencia que ellos mismos. Nuestra presencia y nuestras enseñanzas les sirven para adquirir conocimientos que les llevan a interesarse por lo que sucede fuera de su ambiente $[\ldots] »^{42}$.

Estas respuestas bienintencionadas enfatizaban el hecho de que la profunda represión sociopolítica durante la Dictadura había convertido la relación anteriormente conflictiva entre la clase media conservadora urbana y la clase baja rural de España en un abismo. Las zonas rurales de España eran un dominio totalmente desconocido para las jóvenes mujeres entrevistadas y, mientras que algunas estudiantes, sin duda, ayudaron materialmente a sus familias anfitrionas manteniendo a los niños ocupados e impartiendo clases de lectura y escritura, sorprende su confianza en la idea de que ellas mismas -mujeres jóvenes, solteras, sin hijos y sin experiencia en las tareas del hogar o del campo- eran capaces de cambiar las vidas de mujeres mucho mayores y con más experiencia simplemente por el hecho de pasar un tiempo en el campo.

Otro ejemplo de cómo las nociones de clase distinguían la relación de la SF con respecto a diferentes grupos de mujeres puede encontrarse en la referencia de la organización al asunto del cuidado infantil. La existencia de un servicio de cuidado infantil adecuado es, sin duda, esencial si las mujeres desean poner en práctica su derecho a trabajar. En la década de los sesenta, los redactores de Teresa plantearon una y otra vez la necesidad de disponer de dichos servicios en España. Sin embargo, el discurso sobre instalaciones dedicadas al cuidado infantil para familias de clase media y de clase trabajadora se planteó de forma muy diferente: las instalaciones dedicadas al cuidado infantil para familias de clase trabajadora - guarderías infantiles- funcionaban bajo la supervisión de la SF. Los menores solo eran admitidos si sus madres

41 «Sesenta universitarias de toda España en el SUT», Teresa, núm. 140, agosto 1965

42 Íbid. 
disponían de un certificado que atestiguaba que trabajaban a tiempo completo o en casos en los que la madre sufría una enfermedad crónica y tenía varios hijos en edad preescolar. El precio del servicio era de cinco pesetas por niño y por día ${ }^{43}$. Por otro lado, para las mujeres de clase media existía un servicio a tiempo parcial y de financiación privada llamado babysitting o babyparking. Los dueños de un babyparking en Madrid describieron los servicios que prestaban:

Un niño es un maravilloso problema que madres y padres han de tener presente a todas horas del día. La vida es complicada. Hay viajes ineludibles que realizar, madres que trabajan, falta de servicio, un hermano mayor que se enferma, un nuevo niño que llega al hogar. Son frecuentes las ocasiones en que una madre se encuentra en la necesidad de confiar a su hijo, un bebé de pocos meses, o de tres o cuatro años, que aun no tienen edad escolar, a alguien ${ }^{44}$.

Para las madres de la clase trabajadora, pues, las guarderías infantiles fueron presentadas como un servicio permanente, una realidad constante en las vidas de sus hijos y una oportunidad de asegurar el adoctrinamiento y la educación preescolar dentro de las instituciones de la SF. Para las madres de la clase media, al contrario, los servicios de babysitting constituyeron algo transitorio, tal vez por el número todavía reducido de madres que ejercían una carrera profesional, tal vez por creer que los niños de la clase media estarían mejor cuidados y educados en sus propias casas.

Como se puede ver, el interés de la SF en cambiar la situación legal de la mujer en el mercado laboral español era evidente en las páginas de Teresa. Este interés no se limitaba a profesiones específicas ni a la población de mujeres solteras. Los redactores de Teresa no solo exponían a las mujeres a diferentes opciones profesionales, sino que también debatían las condiciones necesarias para que fueran capaces de satisfacer su vocación profesional. Denunciaban la exclusión de la mujer de los espacios en los que tenía lugar la socialización profesional y la necesidad de marcos de apoyo para mujeres trabajadoras, principalmente en forma de guarderías infantiles. Mientras que muchos colaboradores se referían al trabajo de la mujer como una vocación, y no únicamente como una necesidad económica, los textos de Teresa presentan esta vocación en términos jerárquicos. Las mujeres que trabajaban para lograr satisfacción personal eran, principalmente, mujeres de clase media que tenían algo (conocimientos, apoyo psicológico,

43 "Guarderías infantiles, la SF rige tres en Madrid», Teresa, núm. 145, enero 1966.

44 «BABYPARKING: Una solución si usted no tiene donde dejar a su niño pequeño", Teresa, núm. 187, julio 1969. 
experiencia práctica) que impartir a otros, principalmente a otras mujeres (más jóvenes o con un nivel educativo inferior). Los hombres, que estaban presentes de forma evidentemente abrumadora, estaban prácticamente ausentes del debate sobre la vida profesional de la mujer, como compañeros de trabajo, competidores o como colectivo al que las mujeres tenían algo que aportar. En algún sentido esta ausencia indicaba los límites del debate: si se reconocía el derecho de las mujeres a trabajar, casi nunca se plantearon de forma explicita las implicaciones emocionales, sociales y profesionales de su presencia en un espacio profesional compartido por hombres que no pertenecían a su entorno familiar.

\section{CONCLUSIONES}

Como órgano importante en el seno del régimen de Franco, la SF identificó, durante su existencia, lagunas legislativas, educativas, espacios discursivos y operativos dentro de los que podía intervenir para provocar el cambio en la situación legal, política y profesional de la mujer. Sin embargo, la SF nunca contempló seriamente trabajar contra o fuera del «sistema». Fue precisamente esta característica —el hecho de que la SF nunca fuera considerada una amenaza política seria — la que le permitió actuar como un grupo de presión dentro del régimen y continuar impulsando su propia agenda social y cultural en un ámbito político extremadamente restrictivo.

Como puede observarse en este artículo, el discurso de la SF sobre la posición y el papel de la mujer en la sociedad española intentaba reflejar las diversas experiencias de las mujeres en tiempos de grandes cambios sociales, económicos y políticos, así como sus complejas interacciones con muchos «otros» significativos (maridos, hijos, familiares femeninas mayores, estudiantes y compañeros de trabajo). El énfasis depositado en las acciones e interacciones dentro de este discurso refleja una noción cambiante de la identidad o, al menos, de naturaleza múltiple. Mientras que se animaba a las mujeres a que pensaran en ellas mismas en términos maternales, incluso este aspecto aparentemente esencial de la feminidad se entendía como la contribución específica de las mujeres a la sociedad. Se asumía que las mujeres tenían un instinto de crianza y cuidado al que debían acceder si deseaban explorar su feminidad al completo.

Sin embargo, este instinto no se refería necesariamente a la relación exclusiva, y biológica, entre la madre y el hijo; la maternidad se concibió como una proyección a la sociedad o a la nación de un conjunto de cualidades específicamente femeninas y por lo tanto como una vía particular para el compromiso social de las mujeres. La «maternidad» se utilizaba, frecuentemente, 
como un término intercambiable con «maternidad espiritual», es decir, el cuidado y acogimiento de otras mujeres, compañeros de trabajo más jóvenes y niños que no eran biológicamente suyos. La idea de que las mujeres como grupo tenían una tendencia inherente a preocuparse por el bienestar de otros abría el camino a la participación de las mujeres en todos los ámbitos de la vida — en el lugar de trabajo y la comunidad y como hijas activas y productivas de la patria-.

Mientras que la dirección de la SF intentó hablar con (y en nombre de) todas las mujeres españolas, su discurso sobre el progreso en materia de género estaba condicionado, con frecuencia, por nociones generacionales y de clase específicas. Este condicionamiento permitió que las militantes de la SF mantuvieran intactas sus complejas (y en ocasiones conflictivas) autoidentificaciones. Andrea López (que dirigió la organización de veteranas de la SF Nueva Andadura en Madrid hasta su muerte en mayo de 2006) opinó sobre la singularidad de estas identificaciones: «Siempre nos definimos como Joseantonianas y nuestras instituciones mantuvieron una línea específica» ${ }^{45}$. $\mathrm{Al}$ percibirse como «joseantonias» — es decir, como mujeres activas, educadas, falangistas y católicas al mismo tiempo-, las militantes de la SF luchaban por reconciliar aquello que era casi irreconciliable. Al rechazar el sacrificio de cualquier aspecto de su identidad, construían (en línea con la clásica terminología fascista) un "todo» que era mayor que la suma de sus partes, un «todo» con el cual solo podía identificarse un grupo bien definido y muy reducido de mujeres.

La evolución de Teresa avala el pragmatismo y las limitaciones del discurso del régimen sobre el género y sobre el papel de las mujeres en la sociedad. Señala lo que pudo contenerse dentro del discurso y lo que tuvo que ser expulsado. También pone de relieve la interacción entre los conceptos de género y clase para determinar el «yo» y el «otro» en la sociedad franquista. En los ámbitos de la legislación sobre género, la representación política y las relaciones laborales, la SF trabajó para crear un sistema de valor más liberal que el que apoyaban otros sectores del régimen de Franco. Sin embargo, la negativa de sus militantes a modificar de cualquier forma su compleja serie de alianzas e identificaciones hizo que la SF fuera incapaz de contener las necesidades y aspiraciones cambiantes de miles de mujeres españolas. En estas condiciones, esta élite política femenina que nació en el bastión del fascismo español y que creció hasta convertirse en uno de los órganos más dinámicos del fascismo, no pudo encontrar un lugar en la España democrática.

45 En una entrevista con la autora en Madrid, 15-12-2004. 


\section{Bibliografía}

Basora Francesch, M. (1964). Derecho del Trabajo. Barcelona: Ediciones Ariel.

Bergès, K. (2003). Pilar Primo de Rivera: Cause féminine, idéologie phalangiste, stratégies et enjeux politiques dans l'ombre du régime franquiste [tesis doctoral inédita]. Université de Toulouse-Le Mirail.

Blasco Herranz, I. (1999). Armas femeninas para la contrarrevolución. Málaga: Atenea.

- (2003). Paradojas de la ortodoxia. Política de masas y militancia católica femenina en España (1919-1939). Zaragoza: Prensas Universitarias de Zaragoza.

- (2005). «Sección Femenina» y "Acción Católica»: la movilización de las mujeres durante el franquismo. Revista de Historia Jerónimo de Ustáriz, 21, 55-66.

Borderias, C. (1993). Entre líneas: trabajo e identidad femenina en la España contemporánea. La Compañía Telefónica 1924-1980. Barcelona: Icaria.

Cenarro, A. (2006). La sonrisa de la Falange: Auxilio Social en la Guerra Civil y la posguerra. Barcelona: Crítica.

- (2013). Encuadramiento y consenso en la obra del Movimiento: mujeres, jóvenes, obreros. En M. A. Ruiz Carnicer (coord.). Falange. Las culturas politicas del fascismo en la España de Franco (1936-1975) (pp. 199-200). Zaragoza: Institución Fernando el Católico.

Coca Hernando, R. (1998). Towards a New Image of Women under Franco. International Journal of Iberian Studies, 11, 5-13.

De Diego González, A. (2008). Las mujeres de la Transición. Madrid: Congreso de los Diputados.

Formica, M. (1991). A instancia de parte. Madrid: Biblioteca de Escritoras.

Gallego Méndez, T. (1983). Mujer, Falange y Franquismo. Madrid: Taurus.

Griffin, R. (2010). Modernismo y fascismo. La sensación de comienzo bajo Mussolini y Hitler. Madrid: Akal.

Le Masurier, M. (2014). What is a Magazine? TEXT (Special issue: Australasian magazines. New perspectives on writing), 25, 1-16.

Mañas Viejo, C., Esquembre Cerdá, M., Moreno Seco, M. y Montesinos Sánchez, N. (eds.). (2015). Género y Transición política "Transiciones en marcha». Alicante: Universidad de Alicante.

Martínez Ten, C., Gutiérrez López, P. y González Ruiz, P. (eds.) (2009). El movimiento feminista en España en los años 70. Madrid: Ediciones Cátedra.

Morcillo, A. G. (2000). True catholic womanhood. Gender ideology in Franco's Spain. DeKalb: Northern Illinois University Press.

(2010). The seduction of modern Spain: The female body and the Francoist body politic. New Jersey: Bucknell University Press.

Moreno, M. (2012). Mujeres en la Acción Católica y el Opus Dei. Identidades de género y culturas políticas en el catolicismo de los años sesenta. Historia y Política, 28, 167-194.

Muñoz Sánchez, E. (2006). La imagen de la mujer en las revistas «Teresa» e «Y» de la Sección Femenina. En E. Almarcha Núñez-Herrador, S. García Alcázar y E. Muñoz Sánchez 
(coords.). Fotografía y memoria: I Encuentro en Castilla-La Mancha (pp. 118-128). Ciudad Real: Centro de Estudios de Castilla-La Mancha.

Nielfa Cristobal, G. (ed.) (2003). Mujeres y hombres en la España franquista: sociedad, economía, politica, cultura. Madrid: Editorial Complutense.

Ofer, I. (2006). La legislación de género de la Sección Femenina de la FET. Acortando distancias entre la política de élite y la de masas. Historia y Política, 15, 219-242.

- (2009a). Señoritas in Blue. The making of a female political elite in Franco's Spain. Brighton: Sussex University Press.

- (2009b). The Genealogy of a gender identity: The Sección Femenina de la Falange and the image of the National Syndicalist Woman. European Historical Quarterly, 39, 585-605. Disponible en: https://doi.org/10.1177/0265691409342657.

Palomares Ibáñez, J. M. (2001). La Guerra Civil en la ciudad de Valladolid: entusiasmo y represión en la "Capital del Alzamiento». Valladolid: Ayuntamiento de Valladolid.

Rabazas, T. y Ramos, R. (2006). La construcción de género en el franquismo y los discursos educativos de la Sección Femenina. Encounters on Education, 7, 43-70. Disponible en: https://doi.org/10.15572/enco2006.03.

Richmond, K. (2003). Women and Spanish Fascism: The Women's Section of the Falange 19341959. London: Routledge. Disponible en: https://doi.org/10.4324/9780203380727.

Rodríguez López, S. (2004). La SF y la sociedad almeriense durante el Franquismo: de las mujeres del movimiento al movimiento democrático de mujeres [tesis doctoral inédita]. Universidad de Almería.

Threlfall, M., Cousins, C. y Valiente, C. (eds.) (2005). Gendering Spanish democracy. London: Routledge. 